\title{
The pathology of 111 cases of primary hepatic malignancy collected in the Liverpool region
}

\author{
A. H. CRUICKSHANK \\ From the Department of Pathology, University of Liverpool
}

SYNOPSIS The clinical records and preserved specimens of 111 cases of primary malignant disease of the liver have been analysed. All were diagnosed in the Merseyside area, chiefly in Liverpoot and Birkenhead, and all but nine were Europeans. Necropsy was done in 89.

The tumours consisted of 108 carcinomas, two sarcomas, and one mixed tumour. Liver ce carcinoma was nearly four times more frequent than carcinoma of the intrahepatic bile ducts? Both types were commoner in males, the difference between the sexes being greater in the case of liver cell carcinoma. Predisposing conditions included portal cirrhosis, haemochromatosis, and cystic malformations of bile ducts. The gross and microscopic appearances are described and the pathological effects discussed. Liver cell carcinoma tends to invade and permeate veins withiळ the liver but seems, nevertheless, to remain limited to the liver for longer than carcinoma of the intrahepatic bile ducts. Liver cell carcinoma is more characteristic microscopically. The commonest occupation among the male cases was seafarer.

The files of the Liverpool Cancer Control Organization for the years 1947 to mid-1959 were found to contain entries of over 100 cases of primary liver cancer. Because geographical factors are important in this disease, and since most of our information about primary cancer of the liver is derived from material collected in Africa (Symposium, 1957), or America (Edmondson and Steiner, 1954; Edmondson, 1958), it seemed worth undertaking a study of the Liverpool cases.

About a dozen cases were discarded because the material available was insufficient to substantiate the diagnosis, but sections or preserved tissue with short clinical or necropsy notes were available in 111 cases. The results of a preliminary classification of these cases are given in Table $\mathbf{I}$.

TABLE I

111 CASES OF PRIMARY LIVER MALIGNANCY

\begin{tabular}{lrrr} 
Type of & No. of Cases & \multicolumn{2}{l}{ Sex } \\
\cline { 3 - 4 } Tumour & & Male & Female \\
\hline Carcinoma & 108 & 82 & 26 \\
Sarcoma & 2 & 0 & 2 \\
Mixed & 1 & 0 & 1
\end{tabular}

The rare mixed and mesodermal tumours may be dismissed briefly.

Received for publication 8 August 1960.

\section{MIXED AND MESODERMAL TUMOURS}

The mixed tumour was in a 3-month-old baby gi and caused abdominal distension, raising of the dia phragm, and splaying of the ribs. The tumour which was in the right lobe, had not metastasized but caused death, in the opinion of the pathologis who did the necropsy, by compressing the inferior vena cava to cause profound disturbance of the circulation. Microscopically there were large areảs of well-formed bone, myxomatous areas containing haemopoietic cells, and adenocarcinomatous areas Tumours of this type are well recognized and selected examples from amongst the published cases have been used by Edmondson (1958).

The two patients classed as having sarcoma wew both women in early middle age. In one case the diagnosis was made by biopsy of the hepatic mass during a laparotomy for acute symptoms attributable to haemorrhage from the tumour. The microscopte diagnosis was angiosarcoma. There was no necrops

The other patient also had a sarcoma of blood vascular tissues and both the liver and the spleen were affected. The woman had seemed to be in goof health but died suddenly and at necropsy was fournd to have haemoperitoneum from rupture of a hepat tumour that was diagnosed microscopically as $\mathrm{g}$ haemangioblastoma. The appearances suggested that malignancy had been superimposed upon congenitil 


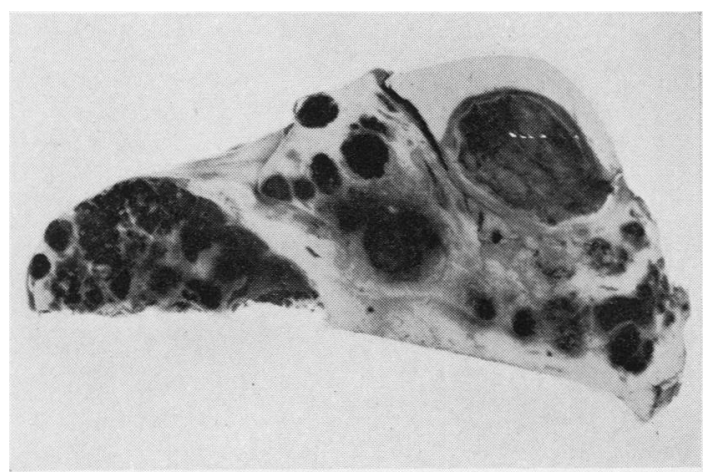

FIG. 1

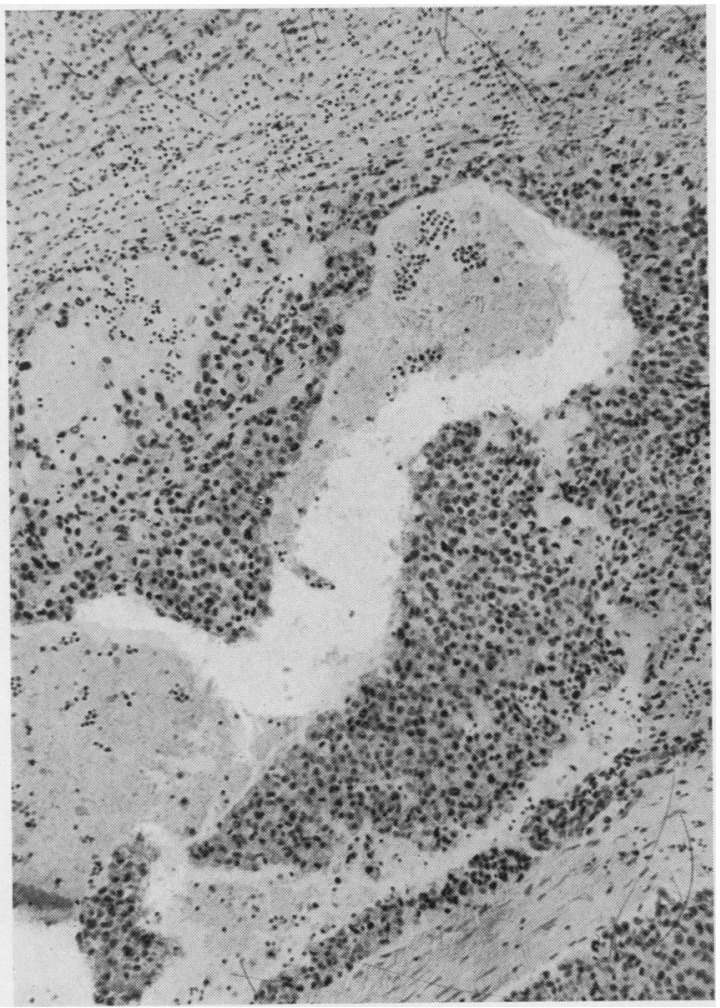

FIG. 2

FIG. 1 Macroscopic appearance of part of a liver almost completely replaced by malignant haemangioblastoma.

FIG. 2. Low-power view of malignant haemangioblastoma. Haematoxylin and eosin $\times 80$.

vascular malformations in the liver. The splenic tumour was similar and may have been metastatic, or a result of simultaneous malignant change in malformed splenic blood channels. Figs. 1 and 2 show the macroscopic and microscopic appearances of parts of the tumour. Cases of this type have been described by Hastings-James (1949), Baker, Paget, and Davson (1956), and Edmondson (1958).

\section{CARCINOMA}

Table II shows that in 20 of the 108 cases diagnosed

TABLE II

CASES OCCURRING IN 1947-59

\begin{tabular}{lccc} 
Diagnosis by & $\begin{array}{c}\text { No. of Cases } \\
\text { of Carcinoma }\end{array}$ & \multicolumn{2}{l}{ Sex } \\
\cline { 3 - 4 } & & Male & Female \\
\hline Necropsy & 88 & 69 & 19 \\
Biopsy & 20 & 13 & 7 \\
Total & 108 & 82 & 26
\end{tabular}

as carcinoma there was no necropsy. Most of these cases, however, had had a laparotomy, had no clinical evidence of a primary growth elsewhere, and had biopsy appearances compatible with primary carcinoma of the liver. The diagnosis 'carcinoma' includes liver cell carcinoma and carcinoma of intrahepatic bile duct epithelium (cholangiocarcinoma).

SEX Male cases predominated by slightly more than 3 to 1 . The greater liability of men to the predisposing conditions of portal cirrhosis and haemochromatosis accounts largely, but perhaps not entirely, for the differing sex incidence. The sex difference was much less in the cases classified histologically as cholangiocarcinoma (Table V).

AGE In both sexes the incidence was highest in the sixth decade but the range was greater in males.

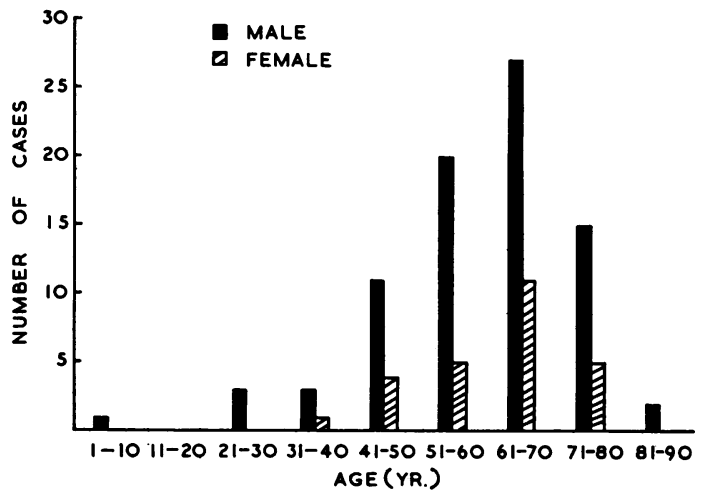

The male cases included one of liver cell carcinoma in a boy 1 year 11 months old, and two cases of men in the ninth decade, one aged 80 and the other 88 , both with liver cell carcinoma. The diagram illustrates the age distribution of the two sexes. 
RACE All the female cases were European. The male cases included nine non-European, of whom four were West Africans, two Indians, two Chinese, and one West Indian of African stock.

OCCUPATION No occupation had been recorded in the notes of 22 of the cases. The occupation of 18 of the 26 female cases was entered as 'housewife'. The commonest occupation amongst the male cases was 'seafarer'. There were 17 cases in this group, including one ship's master, one officer, and four stewards. The group included seven of the nine nonEuropean cases. Other occupational groups were as follows: labourers 10 , clerical 10 , engineers 4 , police 3 , painters 3 , army and R.A.F. 2. The remaining 22 cases had occupations, no two of which were similar.

INCIDENTAL CONDITIONS Gall stones were present or had been removed in 11 cases. Active peptic ulcers or the scars of healed ulcers were recorded in nine cases. A history of syphilis or positive serological tests for syphilis were recorded in six cases.

PREDISPOSING LESIONS The cases with, and without lesions suspected of predisposing to hepatic carcinoma are tabulated in Table III. No cases of infestation by Clonorcis sinensis, whose relationship to carcinoma of small bile ducts has been demonstrated by Hou (1956), were recognized. The lesions considered to be important are shown in Table III.

TABLE III

PRESENCE OR ABSENCE OF PREDISPOSING LESIONS IN 108 CASES OF CARCINOMA

Lesion

No. of Sex
Cases

Male Female

Portal cirrhosis

Haemochromatosis

Banti's syndrome

Cystic malformation of bile ducts

No predisposing lesion

$\begin{array}{rrr}58 & 51 & 7 \\ 7 & 7 & 0 \\ 1 & 0 & 1 \\ 2 & 0 & 2 \\ 40 & 24 & 16\end{array}$

'Portal cirrhosis' This included all types of fibrous disorganization of structure with the exception of the fibrosis of haemochromatosis and biliary cirrhosis. No cases of Wilson's disease were recognized. In a few of the cases alcohol may have been important but in most of the cases the records contained either no entry of the patient's alcohol consumption or indicated temperate habits. No attacks of infective hepatitis were recorded in the case histories.

'Haemochromatosis' The criteria for inclusion in this group were fibrosis of the liver and loading of the liver cells with haemosiderin pigment whose presence could not be explained by previous bloot. transfusions or episodes of haemolysis. Only one of the seven cases had had the diagnosis establishef before necropsy. This was a man, 65 years old at the time of his death, who had attended a diabetis: clinic where he was found to have a pigmented ski and an easily palpable spleen as well as diabetes? Puncture biopsy of the liver established the diagnosis of haemochromatosis. Death was due to a combina $\overrightarrow{0}$ tion of pyaemic infection and diabetic ketosis. At necropsy a small primary carcinoma of liver celko was an incidental finding in the liver along wit marked fibrous haemochromatosis.

In another case the haemochromatosis and ca $\vec{p}$ cinoma of the liver were incidental findings in a mait? who had died of coronary arterial occlusion. He tom had splenomegaly. In a third case the haemochroo matosis and liver tumour were incidental necropsy findings in a man of 78 who had died of cerebellax haemorrhage. The urine had not been examined before or after death.

Of the remaining four patients, there were tw whose urine was recorded as negative for sugar, the others had no record of an examination of the urine. All four had been diagnosed clinically, or at lapare tomy, as having cirrhosis of the liver and in or pigmentation of the skin was recorded. This mas died of haemorrhage into the peritoneum fro the tumour of the liver. One other died from haemorrhage from oesophageal varices, while th $\vec{E}$ other two died of combinations of cachexia and hepatic insufficiency.

All the cases were men, the youngest 57 and the oldest 78. One liver cell carcinoma was in the leffi lobe; all the other tumours were in the right lobe. One of the tumours was an adenocarcinoma of intrahepatic bile duct epithelium, all the othes were liver cell carcinomas. No iron was detected any of the tumour cells by Perls's reaction despite the strong Prussian blue reaction of adjacent nopneoplastic liver cells.

The cholangiocarcinoma had invaded lymph nod near the liver and one of the liver cell carcinom $\$$ had invaded the right side of the diaphragm and the right kidney by direct extension. No tumode was found beyond the liver in the other cases.

'Banti's syndrome' Carcinoma of the liver association with the Banti syndrome is rare and the following case is an unusual one.

A married woman of 55 noticed a 'numbness in he stomach' about a year before her admission to hospitâd. About six months later the abdomen and ankles begạ to swell and this was followed by attacks of pain in the left hypochondrium, sometimes quite severe, though usually lasting for only a few minutes. On her admission to hospital she had slight jaundice with a palpable spleên 
and signs of free fluid in the abdomen. Haemoglobin was $11.4 \mathrm{~g}$. ( $77 \%$ of normal), red cells 3.0 million, platelets 20,000 , and total white cells 800 per c.mm. (50\% neutro-phil polymorphonuclears, $46 \%$ lymphocytes, and $4 \%$ monocytes). Radiologically oesophageal varices were present. During her stay in hospital the white cells increased somewhat but the ascites became worse and had to be tapped. The surgeons were unwilling to undertake any operative treatment and death was the result of haemorrhage from the oesophageal varices. At necropsy the spleen weighed $1,568 \mathrm{~g}$. The liver was scarred and shrunken, weighing only $672 \mathrm{~g}$. Two rounded nodules of necrotic bile-stained tumour were present in the right lobe and microscopically these were areas of bilesecreting liver cell carcinoma.

As the blood picture was that of 'splenic anaemia', and the spleen much enlarged clinically and pathologically, with death from rupture of oesophageal varices, this case can be classified as an example of the Banti syndrome. The severe scarring and shrinkage of the liver suggests that the Banti syndrome may have been preceded by an episode of liver necrosis but no hint of any such episode could be found in the case history.

'Cystic malformations of bile ducts' In two women congenital cysts of the liver were associated with carcinoma of the intrahepatic bile ducts. Both were surgical cases without necropsy confirmation of the diagnosis.

The first case was a 30-year-old housewife who had a laparotomy on 2 October 1950 because of a lump which had been present in the upper abdomen for some months. A cyst was found in the liver. Excision was not attempted but biopsy was carried out. There was a wall of fibrous tissue lined by epithelium that appeared to be biliary. The contents of the cyst were purulent. The patient's general health remained good after the operation and when she was examined eight months later there had been no increase in the palpable mass. Partial hepatectomy was then attempted but had to be abandoned because the tumour was found to have involved the abdominal wall, the diaphragm, and the peritoneum. On biopsy the tumour was found to be a poorly differentiated carcinoma. About 12 days later the patient had the first of a series of haematemeses from which she died.

The second case was a 68-year-old housewife who had indigestion, jaundice, and an enlarged liver. At laparotomy the liver was enlarged by a tumour and contained many small cysts. Cysts were also present in the pancreas. The gall bladder and extrahepatic bile ducts were normal. Biopsy samples of the liver and a lymph node were diagnosed as carcinoma of the intrahepatic bile ducts associated with cystic malformations of the ducts. Secondary carcinoma was present in the lymph node. At the time of her death, two months later, there were radiological signs of secondary tumour in her spine.

Both cases are similar to examples reported by Willis (1943) and by Richmond (1956).
PATHOLOGY OF PRIMARY CARCINOMA OF THE LIVER

ASCITES This was present in 61 of the cases $(56.5 \%)$.

JAUNDICE This was present in 44 of the cases $(40 \cdot 7 \%)$.

SPLENOMEGALY A minor degree of splenic enlargement, up to about $500 \mathrm{~g}$., was relatively common but enlargement likely to be of clinical significance was present in only four cases. Of these two had haemochromatosis, and one had the Banti syndrome.

MACROSCOPIC APPEARANCES The presence or absence of cirrhosis was very important in determining the naked-eye appearances. In the absence of cirrhosis a nodule or mass of pale or slightly bilestained tumour was easily distinguished from the adjacent liver and a provisional diagnosis of primary cancer of the liver could be made if no primary tumour could be found elsewhere. In the presence of cirrhosis the carcinoma was sometimes obvious as white, firm, infiltrating tumour but in some cases the differentation between nodules of liver cell carcinoma and nodules of regenerative hyperplasia of liver cells was sometimes very difficult. In one case the only hint of the presence of carcinoma was that the liver weighed $4.3 \mathrm{~kg}$. After the true state of affairs had been recognized microscopically, inconspicuous invasion of veins could be seen when the cut surface was scrutinized carefully. Fig. 3 is a photograph of a slice of this liver.

In general the carcinomatous nodules tended to be paler than purely regenerative nodules (Fig. 4), and in haemochromatosis the pallor of the tumour against the rusty brown background of the liver was striking. Sometimes invasion and permeation of veins, with or without thrombosis, was obvious to the naked eye (Fig. 5). Invasion of veins was more common in liver cell carcinoma. When there was no invasion of veins and no obvious bile secretion by the tumour even a tentative differentiation between liver cell carcinoma and cholangiocarcinoma was almost impossible macroscopically. Fig. 6 illustrates the naked-eye appearances of a cholangiocarcinoma.

MICROSCOPIC APPEARANCES Liver cell carcinoma could usually be diagnosed more confidently than cholangiocarcinoma, chiefly because it was more difficult to be sure that a cholangiocarcinoma was not a secondary tumour. In the case of liver cell carcinoma the most characteristic pattern was the so-called solid trabecular type illustrated in Figs. 7 and 8. Bile secretion was an excellent indication of 


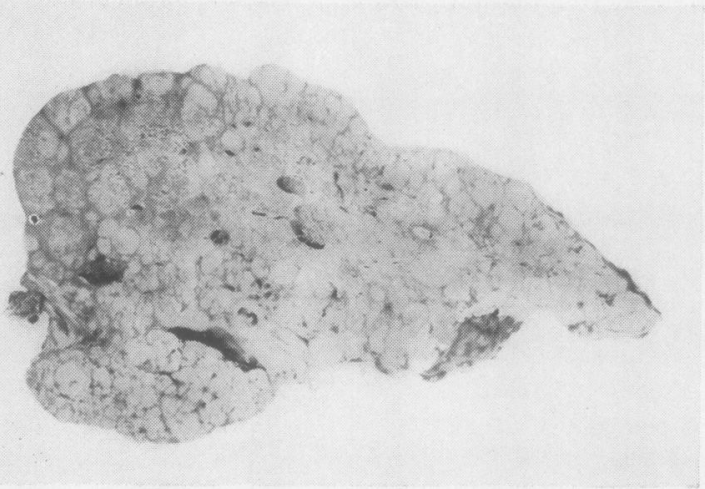

FIG. 3. Nodules of liver cell carcinoma resembling nodular regenerative hyperplasia.

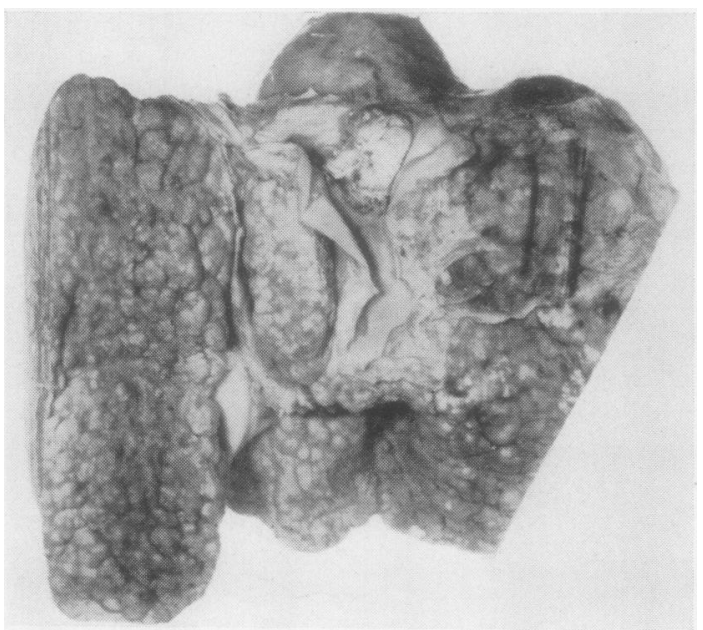

FIG. 5

the nature of the tumour cells and was sometimes present in tumours in which the malignant cells had lost almost all resemblance to liver cells. Fig. 9 illustrates such a tumour which resembled thyroid gland except for bile staining of the secretion in the acini. Other features of liver cell carcinoma were multinucleated giant cells (Fig. 10) and a special tendency to penetrate and permeate veins (Fig. 11). Vacuoles of glycogen or fat were also taken to indicate an origin from liver cells. In many of the cases, however, no material for frozen sections was available. In some cases there was very marked variation in the appearances from place to place (Figs. 12 and 13). Such variation was taken to be evidence in favour of an origin from liver cells because of the tendency for such tumours to form gland-like structures (Steiner, 1959).

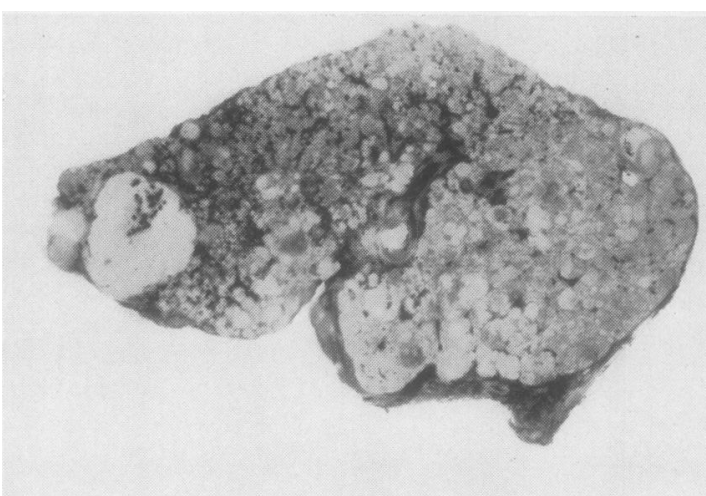

FIG. 4. Pallor of nodule of liver cell carcinoma.

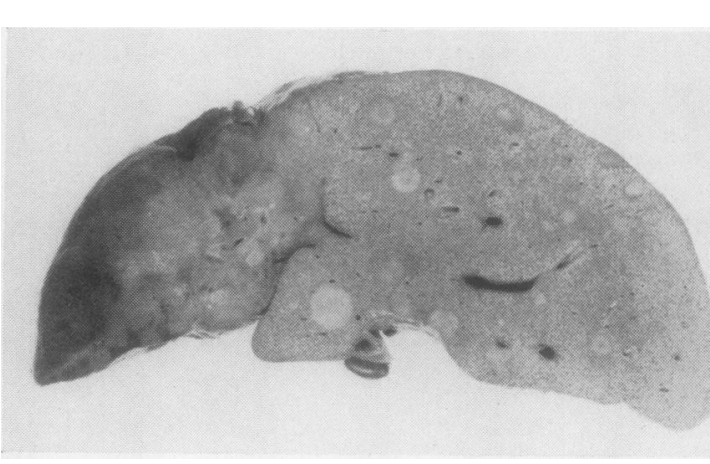

FIG. 6

FIG. 5. Invasion of hepatic veins and inferior vena cava by liver cell carcinoma.

FIG. 6. Cholangiocarcinoma of the left lobe of a noncirrhotic liver with secondary nodules throughout the right lobe.

Cholangiocarcinoma usually had a glandular structure, often papillary (Fig. 14) and sometimes had mucus-secreting, signet ring cells (Fig. 15). The picture was similar to that of carcinoma of the $\Omega$ extrahepatic bile ducts except that large accumu- $N$ lations of extracellular mucus were not seen. One $\underset{\mathrm{N}}{\mathrm{N}}$ case that was forming small cholangiole-like tubules (Fig. 16) was probably of the type that Steiner (1959) has named the cholangiolocellular type.

Table IV indicates how the cases of carcinoma were classified histologically. The seven tumours not assigned to either category were anaplastic and without characteristic features. Liver cell carcinoma $\mathbb{D}$ was considerably more common, $\mathbf{7 4} \cdot 1 \%$ as compared with only $19.4 \%$ of cholangiocarcinomas. Both types were more common in men but the discrepancy 


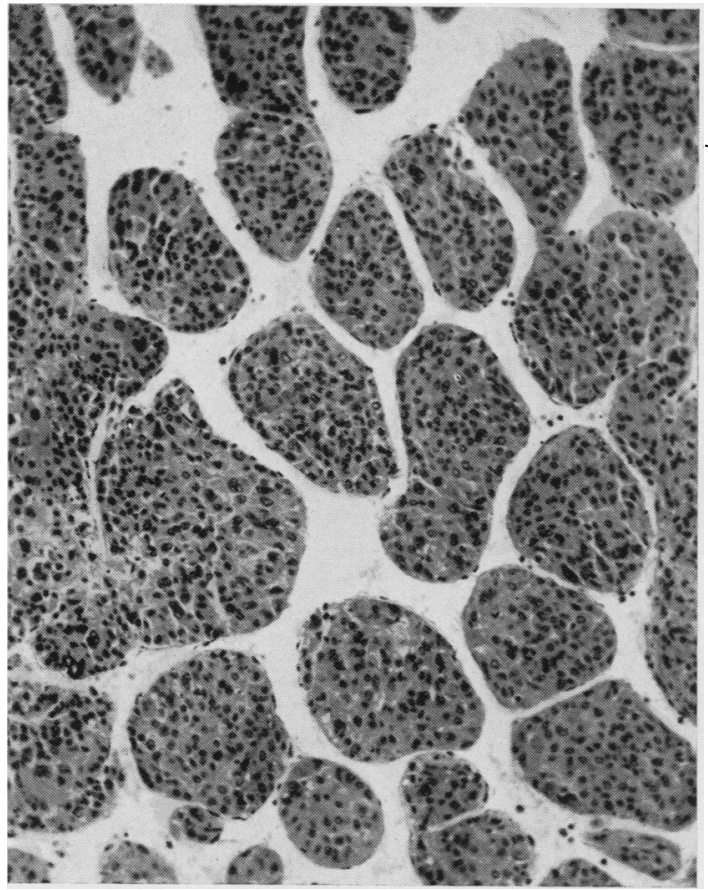

FIG. 7. Solid trabecular pattern in liver cell carcinoma. Haematoxylin and eosin $\times 120$.

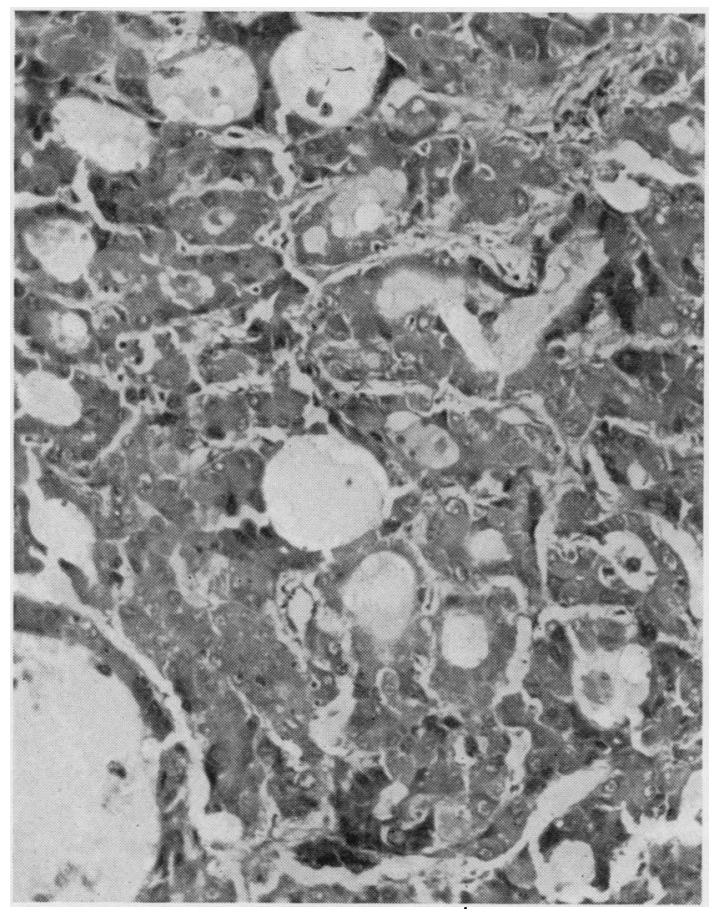

FIG. 9. Thyroid-like structure of a bile-secreting liver cell carcinoma. Haematoxylin and eosin $\times 150$.
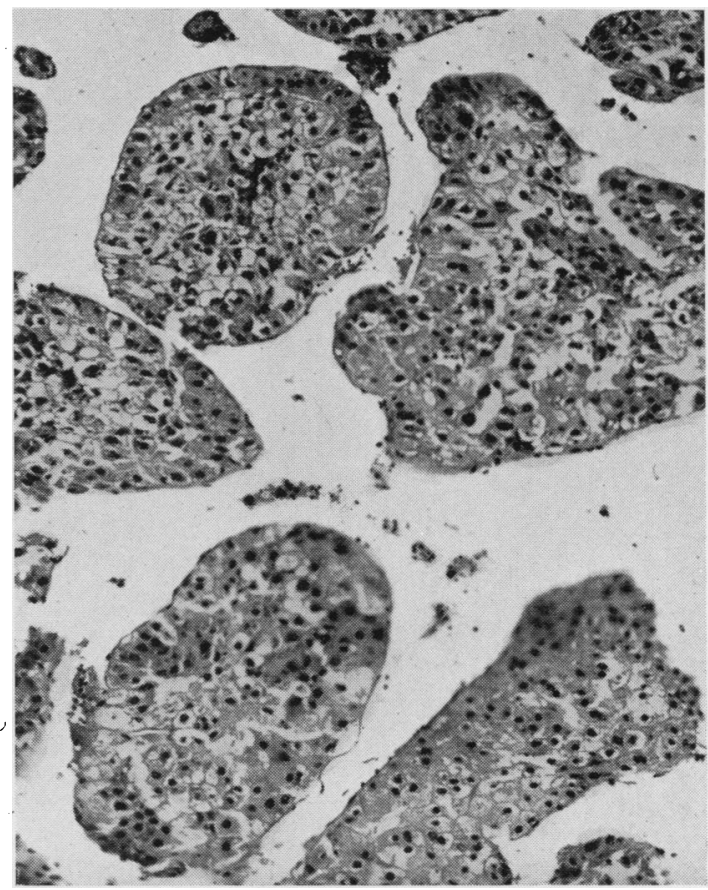

FIG. 8. Solid trabecular pattern with vacuolation.

Haematoxylin and eosin $\times 120$.

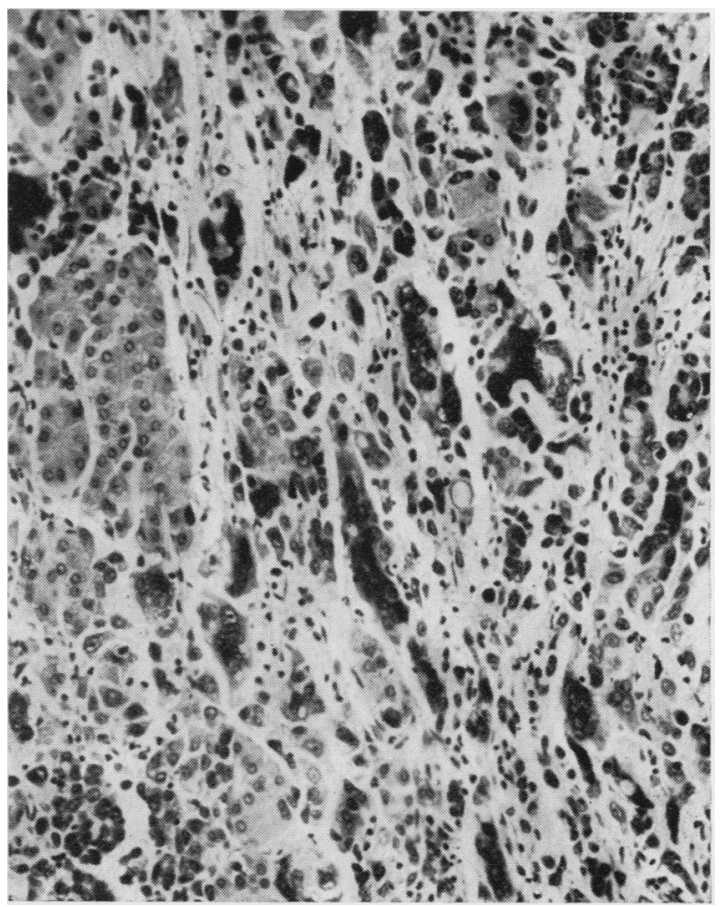

FIG. 10. Multinucleated giant cells in liver cell carcinoma. Haematoxylin and eosin $\times 150$. 


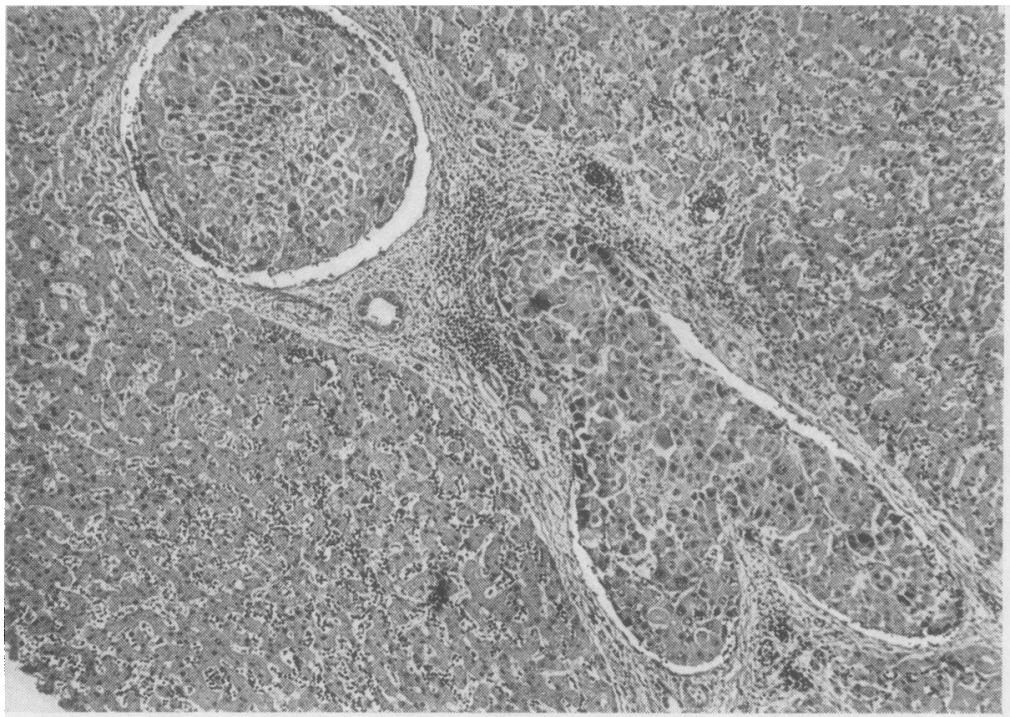

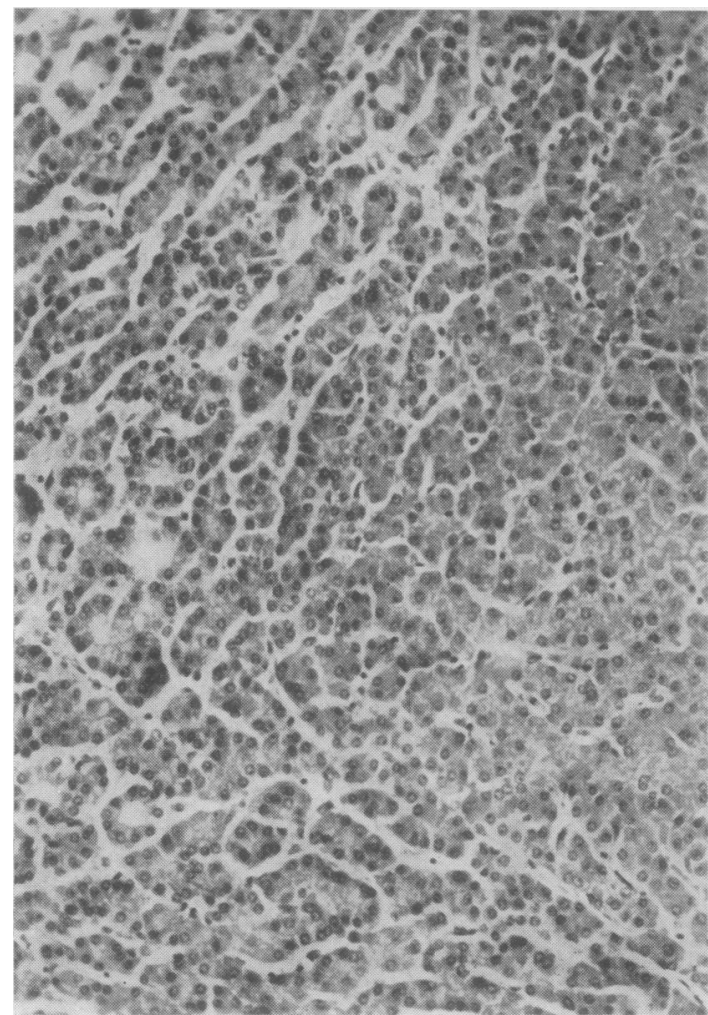

FIG. 12. Well-differentiated area of liver cell carcinoma. Haematoxylin and eosin $\times 150$.

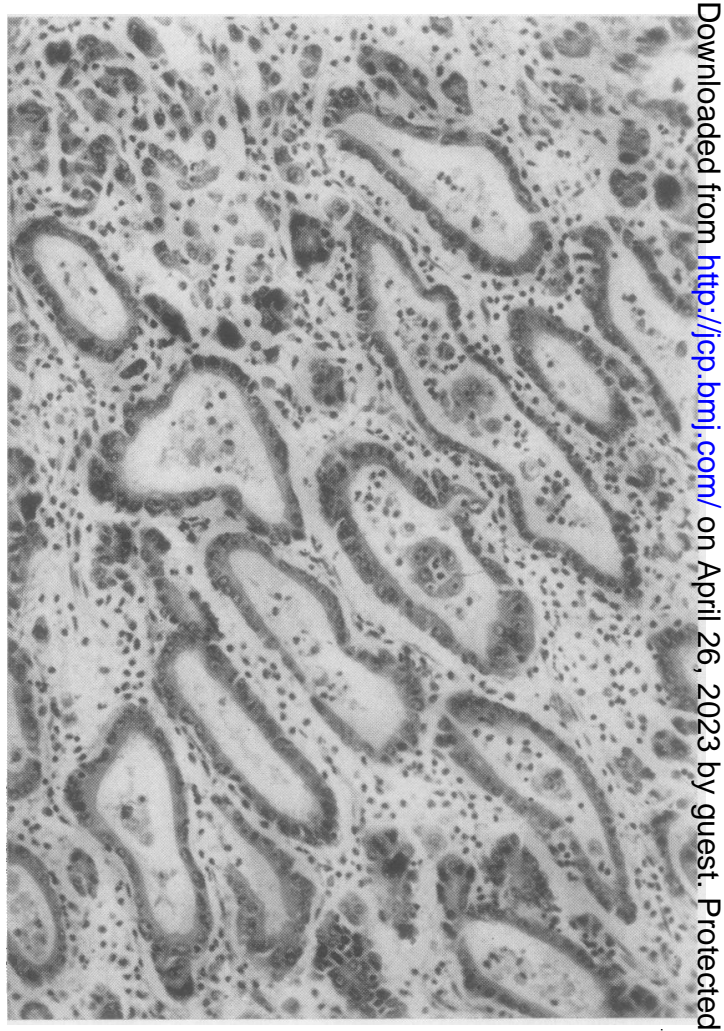

FIG. 13. A different area of the same tumour shown in Fig. 12. Haematoxylin and eosin $\times 150$. 


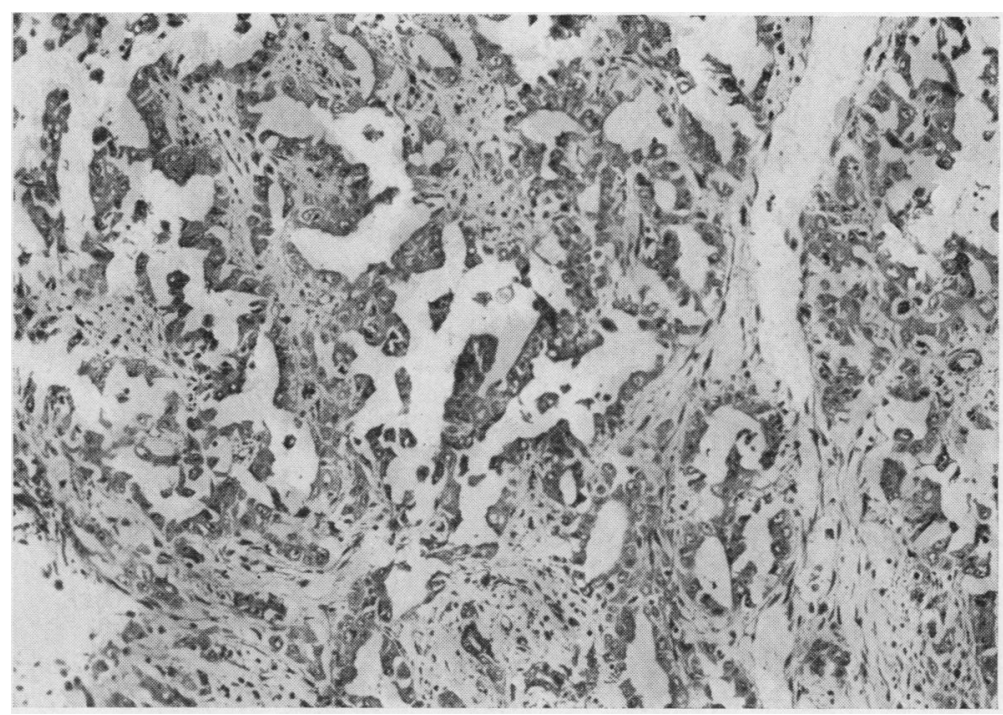

FIG. 14. Slightly papillary adenocarcinomatous cholangiocarcinoma. Haematoxylin and eosin $\times 180$.

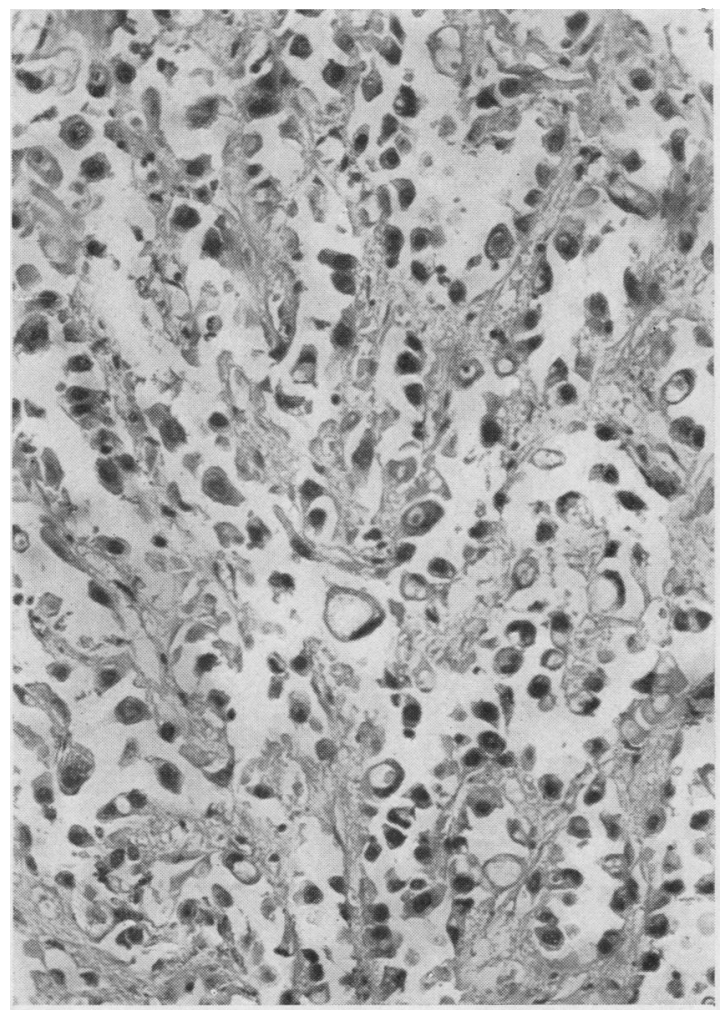

FIG. 15. Signet ring cells in cholangiocarcinoma.

Haematoxylin and eosin $\times 260$.

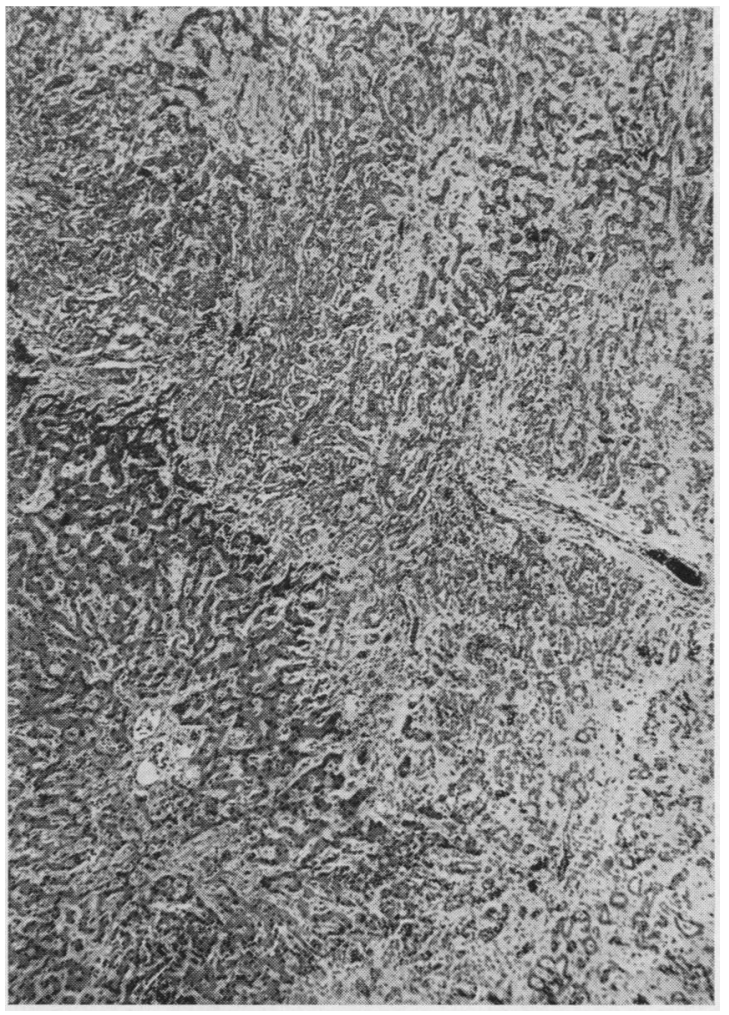

FIG. 16. Cholangiole-like structure of carcinoma of intrahepatic bile duct epithelium. Haematoxylin and eosin $\times 41$. 
TABLE IV

HISTOLOGICAL CLASSIFICATION OF 108 PRIMARY LIVER CARCINOMAS

\begin{tabular}{lcc} 
Type & \multicolumn{3}{l}{ Sex } & \\
\cline { 2 - 3 } & Male & Female \\
\hline Liver cell & 65 & 15 \\
Cholangiocarcinoma & 12 & 9 \\
Indefinite & 5 & 2
\end{tabular}

between the sexes was less in the case of the cholangiocarcinomas.

None of the tumours was classed as being a combination of the two types.

PRESUMED PRIMARY CARCINOID TUMOURS Amongst the tumours of bile duct epithelium there were two that may have originated from argentaffin cells. Tumours suspected to be primary liver tumours of this type are mentioned by Edmondson (1958). One of the Liverpool cases has been reported by Stanley (1958). The patient suffered from the 5HT syndrome and was found to have multiple hepatic tumours. No primary tumour elsewhere was found at necropsy.

The other patient died in 1949 before the 5HT syndrome had been recognized or associated with carcinoid tumours.

A woman of 62 attended hospital in January 1949, because of diarrhoea which she had had for five months. At first she had had two or three bowel motions per day, later the motions increased to five to 10 per day. On examination a swelling was seen in the right hypochondrium and right lumbar region. A barium meal, barium enema, excretion pyelography, and cystogram were negative apart from showing that the pylorus and hepatic flexure of the colon were depressed by a mass in the region of the gall bladder. At operation on 28 January 1949, a firm, rounded swelling, about $3 \frac{1}{2}$ in. in diameter, was found within the substance of the liver immediately deep to the attachment of the falciform ligament. The rest of the liver appeared healthy but the right lobe extended to well below the level of the right kidney. The tumour had a clear line of demarcation from the liver and was enucleated.

The patient made a good recovery from the operation but diarrhoea recurred within a month. For a time her general health improved and her weight increased but this was not maintained and when she was seen seven months after the operation a recurrent mass was felt in the liver beneath the operation scar. Diarrhoea was now very troublesome. She was not seen again but it was learned that she died about four months later. There was no necropsy.

The excised tumour was a lobulated yellowish mass with a smooth outline about $8 \mathrm{~cm}$. in diameter with some cystic blood-filled spaces. Microscopically there were areas, especially at the periphery of the tumour (Fig. 17), where the appearances were those of a carcinoid tumour. Argentaffin granules were demonstrated by Hamperl's

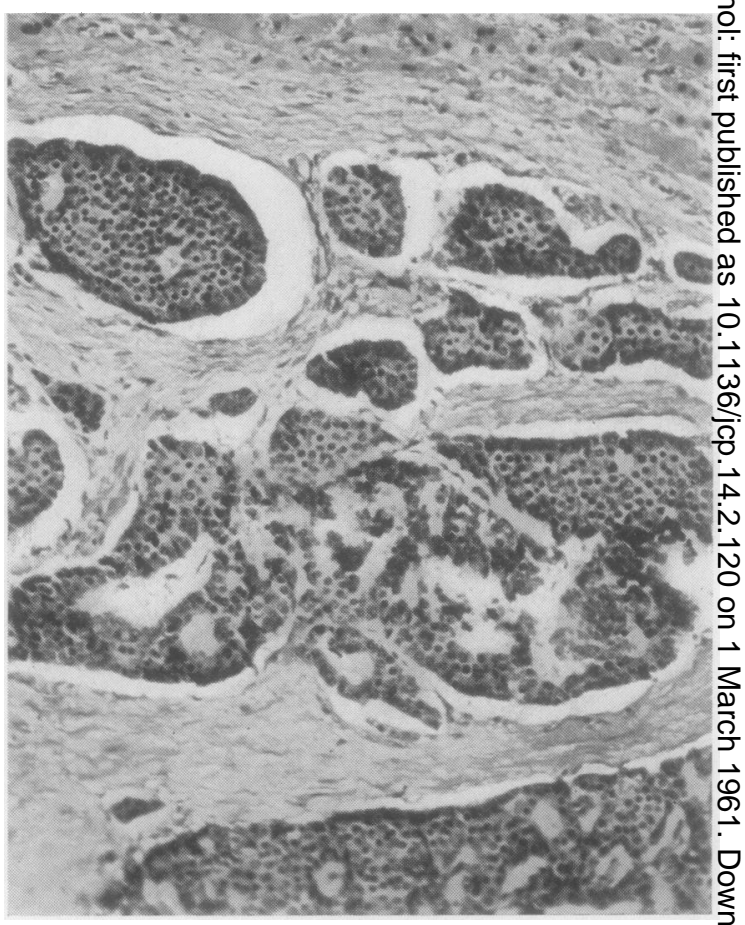

FIG. 17. Carcinoid tumour of the liver, probably primary. Haematoxylin and eosin $\times 150$.

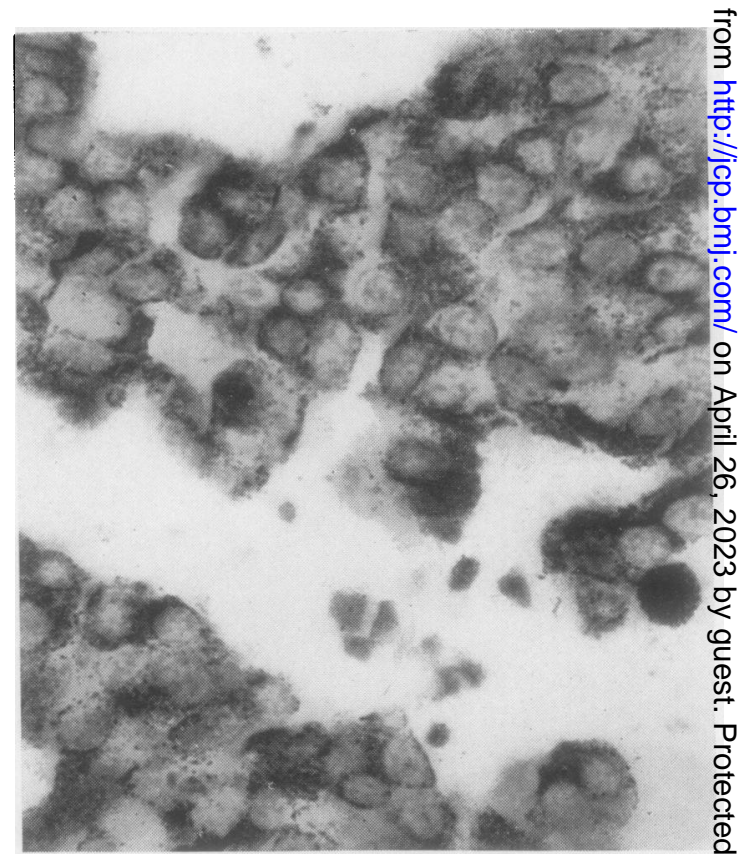

FIG. 18. Argentaffin granules in carcinoid tumour of the liver. Hamperl's protargol $\times 1,600$. 
(1952) protargol method (Fig. 18) and by the alkaline diazo reaction using fast red salt $B$.

This case can only be presumed to be one of primary carcinoid tumour of the liver. The surgical treatment was based on the belief that the tumour was primary in the liver. Throughout the illness diarrhoea was the main symptom but no cause within the bowel was found clinically or on laparotomy. The excision of the tumour produced temporary relief of the diarrhoea and its recurrence coincided with recurrence of the tumour. Apart from the diarrhoea no other features of the 5HT syndrome were noted but at that time the syndrome had not been recognized.

INVASION AND METASTASIS In some of the cases invasion of veins within the liver with superimposed thrombosis was very striking. So far as could be learned from the available information in the 88 necropsy cases the incidence of such thrombosis is given in Table $\mathrm{V}$.

TABLE V

VENOUS THROMBOSIS WITH PRIMARY CARCINOMA OF LIVER

\begin{tabular}{lll} 
Hepatic Portal & $\begin{array}{l}\text { Inferior Vena } \\
\text { Caval }\end{array}$ & Elsewhere \\
\hline
\end{tabular}

Fig. 19 illustrates thrombosis of a large branch of the portal vein. The six cases with thrombosis of veins far from the liver, usually in the legs, were probably examples of the venous thrombosis long known to be common in cases with carcinoma of abdominal organs (Trousseau, 1873).

As has been noted by others, invasion of veins is by no means invariably associated with blood-borne secondary deposits, and invasion of lymph nodes was the commoner type of spread in both liver cell carcinoma and cholangiocarcinoma. Moreover, although invasion of veins was more common in liver cell carcinoma, metastatic deposits were less common with this type of tumour than with cholangiocarcinoma.

DISTRIBUTION OF SECONDARY DEPOSITS Of the 88 necropsy cases, 84 could be classified into liver cell or cholangiocellular types. In the 67 liver cell carcinomas, metastasis had occurred in 22 , approximately one third, while in the 17 cases of cholangiocarcinoma metastasis had taken place in 13 , over three-quarters.

The organs affected were as follows:-

Liver cell carcinoma Lymph nodes in 12 cases, lungs in 10 , diaphragm in 6 , peritoneum in 4 ,

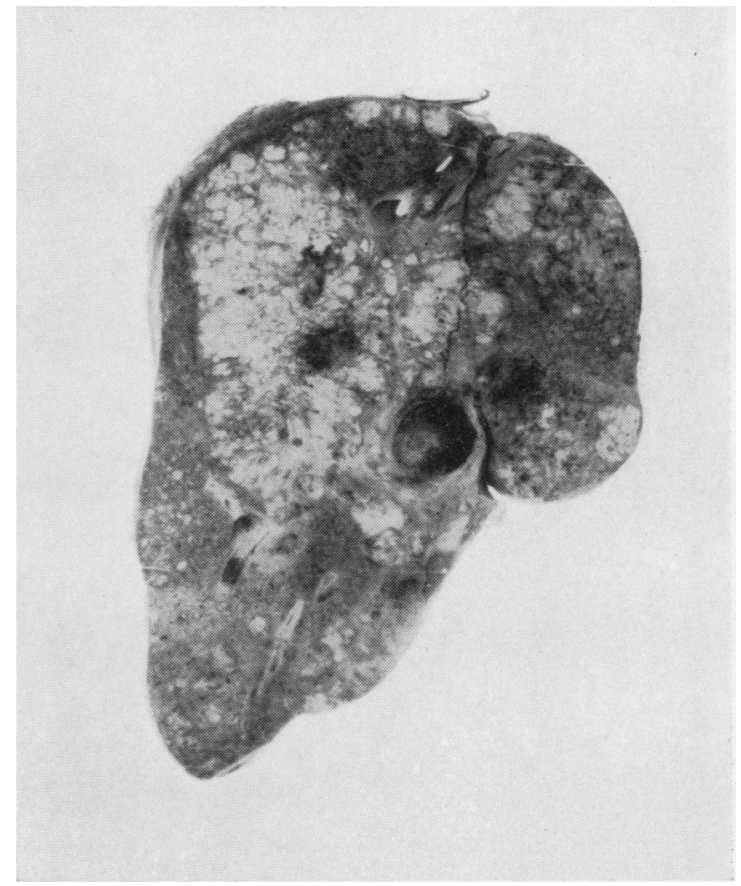

FIG. 19. Thrombosis of the portal vein in a liver cell carcinoma in a cirrhotic liver.

adrenals in 3 , bone in 2 , pleura in 2 , abdominal wall in 1 , heart in 1 , and thyroid in 1 .

Cholangiocarcinoma Lymph nodes in 9 cases, adrenals in 7, lungs in 3, diaphragm in 2, pleura in 2, peritoneum in 2, bone in 2, and kidney in 1 .

In both types the involvement of the diaphragm, abdominal wall, pleura, peritoneum, and, in some cases, the right adrenal, appeared to be by direct extension rather than by the lymphatic or blood systems.

INVASION OF THE BILIARY SYSTEM Edmondson (1958) describes invasion of the common bile duct by a liver cell carcinoma and could find only one report of a case of this type. Invasion of the common duct, with obstructive jaundice as result, was a feature of one of the cases in Liverpool.

An 80-year-old man had a laparotomy for jaundice and an enlarged liver. A cirrhotic liver was found and the gall bladder, which contained stones, was removed. 'Mud' was removed from the common hepatic duct and the duct was drained. The man died six weeks later, and at necropsy a primary liver cell carcinoma that had originated in the cirrhotic liver was found to have invaded and obstructed the common bile duct for a distance of $3 \mathrm{~cm}$. The liver weighed $1,150 \mathrm{~g}$. and there was thrombosis of the left hepatic vein with extension of the thrombosis to the inferior vena cava. The immediate 


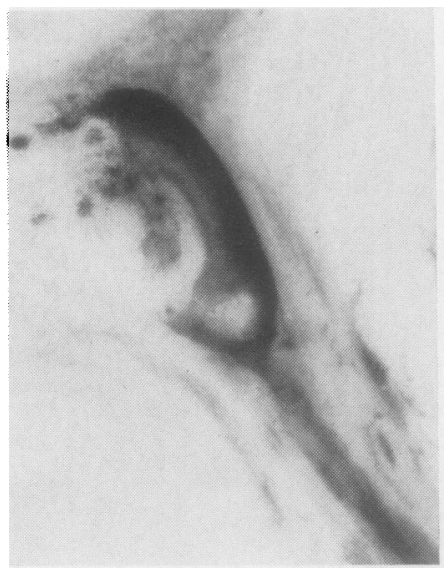

FIG. 20.

Invasion of a bile duct by liver cell carcinoma.

Slightly enlarged.

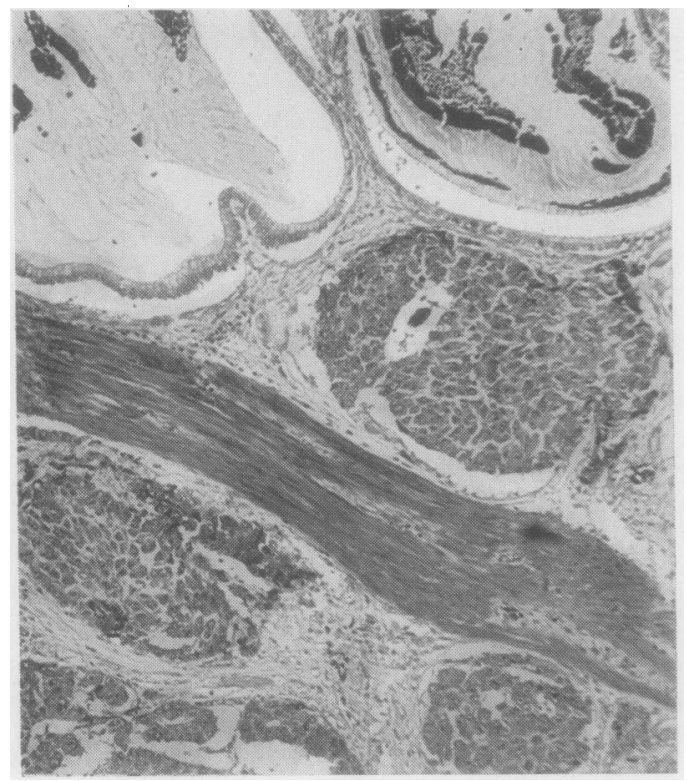

FIG. 21. Wall of gall bladder being invaded by liver cell carcinoma. Normal mucosa with adherent bile and mucus is present on the left. Haematoxylin and eosin $\times 80$.

cause of death was haemorrhagic pericarditis. No secondary deposits beyond the liver and biliary system were found.

Minor degrees of invasion of the biliary system were found in two other Liverpool cases. Fig. 20 shows a primary liver cell carcinoma invading a large bile duct, and Fig. 21 is of a section from another case in which the wall of the gall bladder is being penetrated by a liver cell carcinoma that arose in the non-cirrhotic liver of a 51-year-old woman and caused death by intraperitoneal haemorrhage.
HAEMORRHAGE ASSOCIATED WITH PRIMARY CARCINOMA OF LIVER Haemorrhage from oesophageal varices: is a common manifestation of the disturbance of the portal circulation caused by cirrhosis of the liver and it has been claimed by Hou (1958) that the thrombosis of the branches of the portal vein that is common in primary carcinoma of the liver was associated with oesophageal varices in $89 \%$ of hiß्ड 200 cases of primary carcinoma of the liver in 5 Chinese. The information available in the Liverpoolcases was insufficient to confirm these figures butw haemorrhage was common and was frequently the cause of death. In addition to alimentary bleeding from oesophageal varices haemorrhage was found $\bar{b}$ also to occur into the peritoneal cavity or into the retroperitoneal tissues near the tumour. In a number of cases also, haemorrhage occurred at sites fa? removed from the diseased liver. Some of the haemorrhagic episodes, such as cerebral and cerebellar haemorrhages, were probably unrelate to the disease of the liver, but in some of the othep cases, those with severe epistaxis, for example, it is. possible that a tendency to bleed was a result of liver damage. The following type of haemorrhagic episode occurred in the Liverpool cases: alimentary 26 , peritoneal 16, near tumour 6, distant 18 .

\section{DISCUSSION}

The discovery of 111 cases in the Liverpool region $\vec{B}$ suggested at first that the region had an unusually high incidence of primary malignant tumours of the liver. The incidence is usually expressed as a per? centage of the total number of necropsies dons: during the relevant period, and the total number of necropsies was learned by asking all the pathologists in the region for the numbers of the necropsies in their institutions between 1 January 1947 and 38 June 1959. The information received indicated that the 88 necropsy cases of hepatic carcinoma ha\$ been yielded by 60,600 necropsies, an incidence of $0.145 \%$, almost exactly the incidence for Europegenerally (Berman, 1951). Such an incidence is somewhat less than the $0.2 \%$ found in Los Angeles and Chicago by Edmondson and Steiner (1954), an\& substantially less than the $0.72 \%$ incidence reporte in Boston, Mass., by MacDonald (1957).

Although the incidence in the region as a whof was not unusually high, most of the cases were found in the vicinity of the ports of Liverpool and Birkenhead and the relatively large numbers of seafarers may give an indefinite hint of som $\Phi$ aetiological relationship between seafaring and the्ष disease.

The association with haemochromatosis, $7.95 \%$ of the necropsy cases, is remarkably similar to the 
$7 \cdot 7 \%$ found by MacDonald in Boston, Mass. The lack of splenomegaly, too, in the majority of the Merseyside cases was similar to MacDonald's findings.

In general the Merseyside cases tended to be similar in type and behaviour to the cases studied in America and to a lesser extent to resemble the oriental and African type of case but the cases included such rare types as sarcoma of vascular endothelium, malignant mixed tumour of infancy, carcinoma following congenital cystic disease, and, possibly, primary malignant carcinoid tumour. The cases included two Chinese but no example of carcinoma complicating infestation with Clonorcis sinensis was recognized, and there was no case of carcinoma following accumulation of thorotrast in the liver.

Liver cell carcinoma was about four times more frequent than carcinoma of the intrahepatic ducts but, despite its remarkable tendency to permeate veins within the liver, appeared to be slightly less malignant in its behaviour than cholangiocarcinoma. It was an incidental finding, without metastases, in eight of the 88 necropsy cases, and when metastasis had occurred, lymph nodes were affected more commonly than organs involved by blood spread, perhaps because the veins invaded within the liver were eliminated from the circulation by thrombosis. In the 21 cases of carcinoma of intrahepatic bile ducts, the tumour was the main cause of death in nearly every case.

Calcification of primary carcinoma of liver cells may sometimes be so marked that the liver cannot be cut in the ordinary way (Lynch, 1958). But only microscopic foci of calcification in necrotic areas of tumour were seen in the Merseyside cases and such foci were infrequent and inconspicuous.

There was, unfortunately, insufficient information to indicate whether infective hepatitis or alcoholism had been important aetiologically in any of the cases.

I am indebted to Dr. J. S. Fulton, Director of the Liverpool Radium Institute, for permission to use the records of the Liverpool Cancer Control Organization, and to Dr. E. Mavis McConnell for much assistance in analysing the records and tracing cases.

All the pathologists in the Liverpool Region and Dr. G. Pantin, of the Isle of Man, have assisted by providing sections and by making their records available.

The photography is the work of Mr. F. Beckwith and Mr. D. Andrews, of the Department of Pathology, University of Liverpool.

\section{REFERENCES}

Baker, H. de C., Paget, G. E., and Davson, J. (1956). J. Path. Bact., $72,173$.

Berman, C. (1951). Primary Carcinoma of the Liver, p. 18. Lewis, London.

Edmondson, H. A. (1958). Tumors of the Liver and Intrahepatic Bile Ducts. In Atlas of Tumor Pathology. Section 7, Fasc. 25. Armed Forces Institute of Pathology, Washington D.C.

-, and Steiner, P. E. (1954). Cancer, 7, 462.

Hamperl, H. (1952). Virchow's Arch. path. Anat, 321, 482.

Hastings-James, R. (1949). J. Path. Bact., 61, 49.

Hou, P. C. (1956). Ibid, 72, 239.

(1958). In Cancer, ed. R. W. Raven. Vol. 2, p. 168. Butterworths, London.

Lynch, J. B. (1958). Personal communication.

MacDonald, R. A. (1957). A.M.A. Arch. intern. Med., 99, 266.

Richmond, H. G. (1956). J. Path. Bact., 72, 681.

Stanley, W. J. (1958). Postgrad. med. J., 34, 643.

Steiner, P. E. (1959). In Modern Trends in Pathology, ed. D. H. Collins, p. 161. Butterworths, London.

Symposium on Cancer of the Liver Among African Negroes (1957). Acta Un. int. Cancr., 13, 507.

Trousseau, A. (1873). Clinique médicale de l'Hôtel-Dieu de Paris, 4th ed., Vol. 3, p. 700. Baillière, Paris.

Willis, R. A. (1943). J. Path. Bact., 55, 492. 